\title{
Seizure Control in Neonates Undergoing Screening vs Confirmatory EEG Monitoring
}

Courtney J. Wusthoff, MD, MS, Vandana Sundaram, MPH, Nicholas S. Abend, MD, MSCE, Shavonne L. Massey, MD, MSCE, Monica E. Lemmon, MD, Cameron Thomas, MD, MS, Charles E. McCulloch, PhD, Taeun Chang, MD, Janet S. Soul, MDCM, Catherine J. Chu, MD, MA, MMSc, Elizabeth E. Rogers, MD, Sonia Lomeli Bonifacio, MD, Maria Roberta Cilio, MD, PhD, Hannah C. Glass, MDCM, * and Renée A. Shellhaas, MD, MS,* on behalf of the Neonatal Seizure Registry Group

Neurology ${ }^{\circledR}$ 2021;97:e587-e596. doi:10.1212/WNL.0000000000012293

\section{Abstract}

\section{Objective}

To determine whether screening continuous EEG monitoring (cEEG) is associated with greater odds of treatment success for neonatal seizures.

\section{Methods}

We included term neonates with acute symptomatic seizures enrolled in the Neonatal Seizure Registry (NSR), a prospective, multicenter cohort of neonates with seizures. We compared 2 cEEG approaches: (1) screening cEEG, initiated for indications of encephalopathy or paralysis without suspected clinical seizures; and (2) confirmatory cEEG, initiated for the indication of clinical events suspicious for seizures, either alone or in addition to other indications. The primary outcome was successful response to initial seizure treatment, defined as seizures resolved without recurrence within 30 minutes after initial loading dose of antiseizure medicine. Multivariable logistic regression analyses assessed the association between cEEG approach and successful seizure treatment.

\section{Results}

Among 514 neonates included, 161 (31\%) had screening cEEG and 353 (69\%) had confirmatory cEEG. Neonates with screening cEEG had a higher proportion of successful initial seizure treatment than neonates with confirmatory cEEG (39\% vs $18 \%$; $p<0.0001)$. After adjusting for covariates, there remained a greater odds ratio (OR) for successful initial seizure treatment in the screening vs confirmatory cEEG groups (adjusted OR 2.44, 95\% confidence interval 1.45-4.11, $p=0.0008)$.

\section{Conclusions}

These findings provide evidence from a large, contemporary cohort of neonates that a screening cEEG approach may improve odds of successful treatment of acute seizures.

\author{
Correspondence \\ Dr. Wusthoff \\ wusthoff@stanford.edu
}

MORE ONLINE

(III) Class of Evidence Criteria for rating therapeutic and diagnostic studies

NPub.org/coe

\section{CME Course}

NPub.org/cmelist

\footnotetext{
*These authors contributed equally to this work.

From the Divisions of Child Neurology and Pediatrics (Neonatology) (C.J.W.) and Division of Neonatal \& Developmental Medicine, Department of Pediatrics (S.L.B.), Stanford University; Quantitative Sciences Unit (V.S.), Department of Medicine, Stanford University School of Medicine, Palo Alto, CA; Departments of Neurology (N.S.A., S.L.M.), Pediatrics (N.S.A., S.L.M.), and Anesthesia \& Critical Care Medicine (N.S.A.), University of Pennsylvania Perelman School of Medicine; Department of Pediatrics (Division of Neurology) (N.S.A., S.L.M.), Children's Hospital of Philadelphia, PA; Departments of Pediatrics and Population Health Sciences (M.E.L.), Duke University School of Medicine, Durham, NC; Department of Pediatrics (C.T.), College of Medicine, Division of Neurology, Cincinnati Children's Hospital Medical Center, University of Cincinnati, OH; Departments of Epidemiology and Biostatistics (C.E.M., H.C.G.) and Pediatrics (E.E.R.) and Department of Neurology and Weill Institute for Neuroscience and Department of Pediatrics, UCSF Benioff Children's Hospital (H.C.G.), University of California San Francisco; Neurology (T.C.), George Washington University School of Medicine, Children's National Hospital, Washington, DC; Department of Neurology (J.S.S.), Boston Children's Hospital, Harvard Medical School, MA; Department of Neurology (C.J.C.), Massachusetts General Hospital, Harvard Medical School, Boston; Division of Pediatric Neurology (M.R.C.), Department of Pediatrics, Saint-Luc University Hospital, Université Catholique de Louvain, Brussels, Belgium; and Division of Pediatric Neurology (R.A.S.), Department of Pediatrics, Michigan Medicine, University of Michigan, Ann Arbor.
}

Go to Neurology.org/N for full disclosures. Funding information and disclosures deemed relevant by the authors, if any, are provided at the end of the article.

The Article Processing Charge was funded by the authors.

This is an open access article distributed under the terms of the Creative Commons Attribution-NonCommercial-NoDerivatives License 4.0 (CC BY-NC-ND), which permits downloading and sharing the work provided it is properly cited. The work cannot be changed in any way or used commercially without permission from the journal. 


\section{Glossary}

ASD = absolute standardized difference; ASM = antiseizure medication; $\mathbf{c E E G}=$ continuous EEG; $\mathbf{C I}=$ confidence interval; HIE = hypoxic-ischemic encephalopathy; NICU = neonatal intensive care unit; NSR = Neonatal Seizure Registry; OR = odds ratio.

\section{Classification of Evidence}

This study provides Class III evidence that for neonates a screening cEEG approach, compared to a confirmatory EEG approach, increases the probability of successful treatment of acute seizures.

Seizures in neonates are difficult to diagnose and often refractory to treatment. Up to two-thirds of neonates with acute symptomatic seizures have incomplete response to the initial loading dose of antiseizure medication (ASM). ${ }^{1}$ Strategies to improve treatment of neonates with seizures include the use of continuous EEG monitoring (cEEG) to accurately diagnose seizures and assess response to treatment. ${ }^{2}$ It is unknown whether preemptive use of cEEG to screen for seizures in high-risk neonates improves odds of treatment success, as compared to initiating cEEG to confirm the diagnosis of seizures only after clinically suspected seizures occur.

We hypothesized that utilization of a screening CEEG rather than a confirmatory cEEG approach would improve the likelihood of prompt and successful response to initial ASM treatment for neonates with acute symptomatic seizures.

\section{Methods}

The primary research question of this study was to provide Class III evidence for whether in neonates a screening cEEG approach rather than a confirmatory cEEG approach is associated with increased probability of successful treatment of acute seizures.

\section{Study Design}

We performed secondary analyses of data from the Neonatal Seizure Registry (NSR), a prospective registry of neonates with acute symptomatic seizures managed at 9 centers that adhere to the cEEG guidelines of the American Clinical Neurophysiology Society ${ }^{2}$ from July 2013 through March 2018. The methods of the NSR have been reported previously. ${ }^{1}$

For these analyses, data from 2 prospective cohorts were merged. NSR-I was a consecutive cohort of all neonates with seizures diagnosed clinically or with cEEG confirmation, enrolled under a waiver of consent from January 2013 to November 2015. NSR-II was a nonconsecutive cohort of neonates who survived acute symptomatic seizures diagnosed clinically or with cEEG confirmation enrolled with parental informed consent from July 2016 to March 2018. While all neonates with suspected seizures underwent cEEG as per American Clinical Neurophysiology Society guidelines, including continuing cEEG until no seizures had occurred for at least 24 hours, and continuing cEEG for the duration of therapeutic hypothermia for infants treated for hypoxicischemic encephalopathy (HIE), the initiation and discontinuation times for cEEG were determined by treating clinicians. Similarly, seizure treatment regimens were at the discretion of the treating clinicians. Neonates from these NSR cohorts have been previously reported. ${ }^{1,3-5}$

For these analyses, we included term neonates (born at $\geq 37$ weeks gestational age) with seizure onset prior to 44 weeks postmenstrual age and acute symptomatic neonatal seizures due to an identified etiology, as determined by site investigator review of clinical documentation (figure 1). Acute symptomatic causes of neonatal seizures included HIE, ischemic stroke, intracranial hemorrhage, infection, and other acute brain injury as specified by the site investigator. Neonates were excluded if they had a transient cause of seizures (e.g., electrolyte abnormalities), had genetic or structural causes of neonatal epilepsy (rather than acute symptomatic seizures), or were missing data on either the cEEG approach used or the primary outcome. As the primary outcome for this analysis was seizure resolution as defined by EEG, we excluded NSR participants who never had seizures on cEEG at the study center (i.e., those with clinically diagnosed seizures that resolved prior to EEG, or those with seizures only reported on outside hospital EEG and not at the NSR study site CEEG). These neonates were included in a sensitivity analysis, as described below and in figure 2 .

\section{Definitions of Outcomes and Independent Variables}

Our primary objective was to assess the association of cEEG approach with successful response to initial seizure treatment without seizure recurrence as confirmed on cEEG. Neonates were categorized as undergoing cEEG according to 1 of 2 monitoring approaches. A screening cEEG approach included neonates with cEEG ordered for sole indications of "encephalopathy" or "paralysis." A confirmatory cEEG approach included neonates with cEEG ordered for indications of "clinical events suspicious for seizures" or "clinical events and encephalopathy," either alone or in addition to other indications. The indication for cEEG was defined as the indication documented in the medical record. The primary outcome was successful response to initial treatment, defined as resolution 


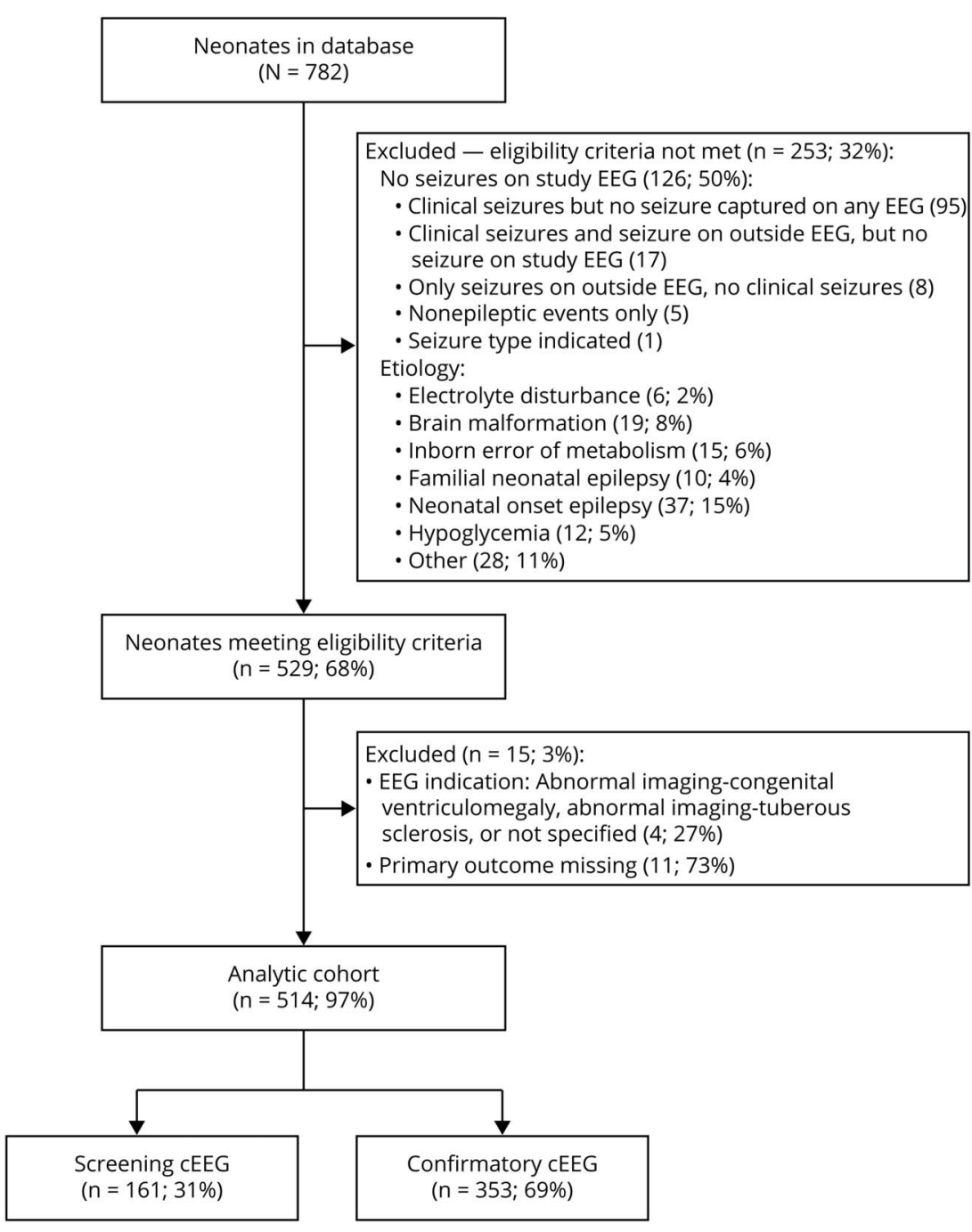

CEEG = continuous EEG.

of seizures on EEG no later than 30 minutes after administration of initial minimum loading dose of ASM (phenobarbital $20 \mathrm{mg} / \mathrm{kg}$, phenytoin or fosphenytoin $15 \mathrm{mg} / \mathrm{kg}$, or levetiracetam $40 \mathrm{mg} / \mathrm{kg}$ ). Successful response to treatment required no relapse, either on EEG or by clinically diagnosed seizures, for the remainder of the neonatal intensive care unit (NICU) admission. The primary seizure etiology was categorized by the site investigator as HIE, ischemic stroke, intracranial hemorrhage, or other etiology. Multiple seizure etiologies were possible for a single patient.

\section{Statistical Analyses}

Descriptive statistics characterized the cohort and compared cEEG groups by age, sex, race, ethnicity, birthweight, Apgar scores, and seizure etiology. The cEEG groups were described and compared for high seizure burden (defined as "frequent recurrent EEG seizures" or status epilepticus) and status epilepticus at any time during NICU admission; the registry data did not include details as to the timing of high seizure burden or status epilepticus. Categorical variables were summarized using frequencies and percentages. Continuous variables were summarized using either mean with $\mathrm{SD}$ or median with interquartile range. Characteristics of the 2 cEEG groups were compared using absolute standardized difference (ASD), which was calculated as the difference in means or proportions divided by the standard error or multivariate Mahalanobis distance method. An imbalance between study groups was defined as ASD values greater than $0.2 .^{6}$

The primary outcome of successful seizure treatment response was analyzed using bivariate and multivariable logistic regression analyses. Seizure severity has been associated with response to treatment; NSR data did not include detail regarding pretreatment seizure severity, but we adjusted for potential confounders previously identified as associated with seizure severity. ${ }^{1}$ The following variables were included in the multivariable analysis as potential confounders related to seizure severity: Apgar score at 5 minutes, primary seizure 


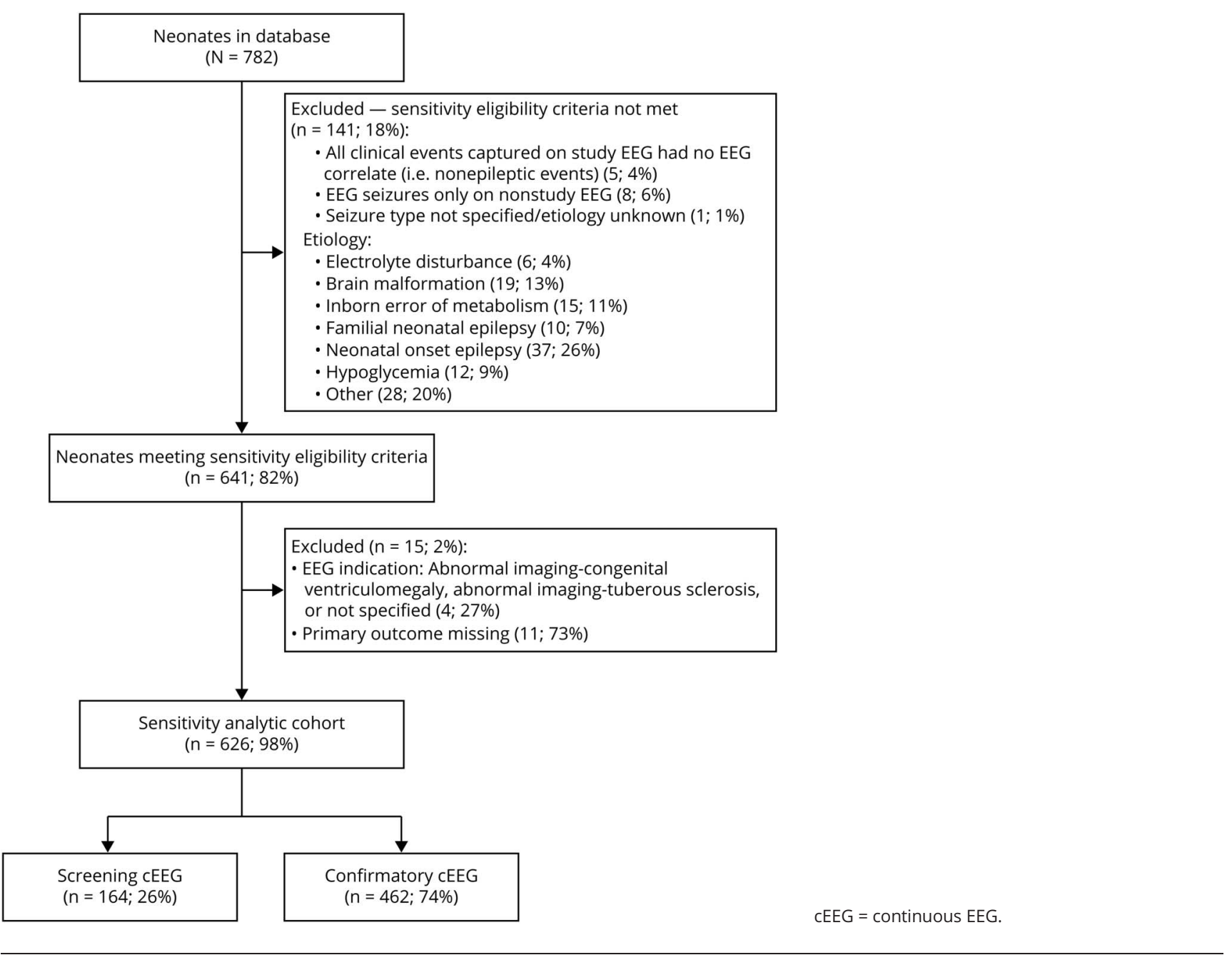

etiology category, presence/absence of multiple seizure etiologies, and whether the patient underwent therapeutic hypothermia.

Because HIE is a common clinical indication for cEEG, and thus of particular clinical interest, an exploratory analysis of the primary outcome was conducted restricting the analytic cohort to newborns who had a primary seizure etiology of HIE. In this analysis, the multivariable logistic regression model included Apgar score at 5 minutes and whether the patient underwent therapeutic hypothermia as potential confounders related to seizure severity.

Sensitivity analyses were performed to consider the potential effect of excluding neonates who never had seizures on study center cEEG (i.e., those with clinical events that resolved prior to EEG or those with clinical seizures and seizures reported on non-study site EEG but never on study EEG), and thus could not be assessed for the primary outcome of seizure resolution on cEEG. The documented indication for cEEG was used to classify these neonates into their cEEG approach group. Simulation studies were conducted to generate missing outcome data by varying the assumption of treatment success (had EEG been available at the time of initial treatment). Treatment success rates simulated were 10\%, 20\%, 25\% (the overall rate of treatment success in the primary analysis), $40 \%$ (the rate of treatment success observed in the screening cEEG group), $60 \%, 80 \%$, and $100 \%$. We also conducted simulations to determine the presumed treatment success rate at which there would be no difference between the 2 cEEG approach groups. Multivariable logistic regression was conducted using the same approach as used for the primary analysis to calculate the mean odds ratio (OR) and 95\% confidence interval (CI) for 1,000 replications of each simulation study.

Unless otherwise specified, all statistical tests were interpreted at a 2 -sided significance level of 0.05 .

\section{Power Analysis}

We expected to include 534 infants in our analysis: 107 in the screening cEEG group and 427 in the confirmatory cEEG group. Based on prior work from the NSR, the overall rate of success with initial seizure treatment was estimated at $33 \%{ }^{1}$ Using these sample sizes, we estimated over $80 \%$ power to 
detect a difference of $15 \%$ in the successful seizure treatment response rate between the cEEG approach groups at a 2 -sided a level of 0.05 .

\section{Standard Protocol Approvals, Registrations, and Patient Consents}

The study was approved by institutional review boards at each center. Data from neonates in NSR were collected under an approved waiver of consent. Data from neonates in NSR-II were collected after written informed consent was obtained from guardians of all participants in this research. The NSR-II study was prospectively registered at ClinicalTrials.gov (NCT02789176).

\section{Data Availability}

Anonymized data from this study will be shared upon request of qualified investigators upon institutional review board approval after the end of the overall study.

\section{Classification of Evidence}

The study is rated Class III because of confounding by indication: screening cEEG was initiated for encephalopathy or paralysis without suspected clinical seizures, and confirmatory cEEG was initiated for clinical events suspicious for seizures.

\section{Results}

\section{Characteristics of Patients in the cEEG Groups}

Among 782 neonates in the dataset, 514 neonates were included in the primary analysis (figure 1). Among these neonates, 161 (31\%) had screening cEEG and 353 (69\%) had confirmatory cEEG. Among the 161 neonates with cEEG ordered for a screening indication, 10 developed clinically apparent seizures after cEEG was ordered but prior to initiation of cEEG. Similarly, of the 353 neonates with confirmatory cEEG ordered to evaluate events deemed suspicious enough to warrant cEEG for differential diagnosis, only 312 had clinical events of high enough suspicion that they were clinically diagnosed as seizures. Table 1 summarizes clinical and demographic characteristics. Neonates in the 2 cEEG groups differed in their primary seizure etiology (ASD 0.87): $75 \%$ in the screening cEEG group had HIE as their etiology vs $34 \%$ in the confirmatory cEEG group. Similarly, therapeutic hypothermia treatment differed (66\% screening cEEG vs $15 \%$ confirmatory cEEG; ASD 1.2). Fifty-nine (12\%) patients died during their neonatal admission, including 25 $(16 \%)$ in the screening cEEG group and $34(10 \%)$ in the confirmatory cEEG group.

\section{Association of cEEG Approach With Treatment Success}

Neonates in the screening cEEG group had a higher proportion of successful response to seizure treatment as compared to neonates in the confirmatory cEEG group (39\% vs $18 \% ; p<0.0001$ ) (table 2). Odds of successful response to seizure treatment remained greater in the screening cEEG group as compared to the confirmatory cEEG group after adjusting for covariates (adjusted OR 2.44, 95\% CI 1.45-4.11; $p=0.0008$ ). Similarly, among the subgroup of 241 neonates with HIE, the screening cEEG group had greater odds of successful response to seizure treatment as compared to the confirmatory cEEG group after adjusting for covariates (adjusted OR 2.15, 95\% CI 1.14-4.04; $p=0.02$ ).

\section{Sensitivity Analysis: Including Neonates Who Never Had Seizures on Study EEG}

The primary analysis excluded 112 neonates with resolution of clinical events prior to study cEEG initiation, as this rendered us unable to measure the primary outcome of seizure resolution on EEG within 30 minutes of initial ASM loading dose (figure 1). Of these neonates, $3(3 \%)$ were in the screening cEEG group and 109 (97\%) were in the confirmatory cEEG group (figure 2). For the 3 neonates with clinical events resolved prior to cEEG initiation but assigned to the screening group, cEEG was ordered for the indication of screening, then clinical events began and resolved in the interval between the decision to order EEG and cEEG initiation.

Figure 3 shows the results of the analyses of simulated data under various assumptions of initial treatment response for the group with clinical events resolved prior to cEEG initiation. When the estimated treatment success rate for those with missing outcome data was $25 \%$ or $40 \%$, the odds of seizure treatment success remained greater in the screening cEEG group as compared to the confirmatory cEEG group. Specifically, if the overall treatment success rate was assumed to be equal to that of the overall cohort from the primary analysis (25\%), then neonates in the screening cEEG group continued to have greater odds of successful seizure treatment response after adjusting for covariates (adjusted OR 2.24, 95\% CI $1.40-3.58)$. Only with assumed rates of successful response to initial treatment greater than $52 \%$ for those with missing data was there no difference between the 2 cEEG approach groups in their successful response to initial treatment (figure 3). EEGbased studies have shown neonatal seizure treatment success rates of 30\%-50\% ${ }^{1,7-9}$; all simulations based on assumptions in this range supported greater odds of successful seizure treatment response in the screening cEEG group.

\section{Discussion}

Seizures are common among neonates with certain high-risk conditions, and they often lack distinct clinical signs. ${ }^{2,10,11}$ Accurate diagnosis of neonatal seizures relies on EEG confirmation. Screening cEEG allows detection of electrographiconly seizures and definitive diagnosis of clinically suspected seizures. Furthermore, in neonates, ASM administration can result in suppression of outward clinical signs while electrographic seizures persist (known as electroclinical "uncoupling"); cEEG is necessary to accurately assess response to ASM treatment. For this reason, some centers have developed pathways to employ cEEG for seizure detection among all neonates in high-risk groups, such as those with HIE or other conditions. ${ }^{12}$ Similarly, the American Clinical Neurophysiology Society has published guidelines for clinical conditions in which cEEG is indicated due to a high risk of seizures. ${ }^{2}$ The American Academy of Pediatrics has suggested that centers 
Table 1 Demographic and Clinical Characteristics by Continuous EEG Monitoring (cEEG) Approach

\begin{tabular}{|c|c|c|c|}
\hline & \multicolumn{2}{|l|}{ cEEG approach } & \multirow{2}{*}{$\begin{array}{l}\text { Absolute standardized } \\
\text { difference }^{a}\end{array}$} \\
\hline & Screening CEEG $(n=161)$ & Confirmatory cEEG $(n=353)$ & \\
\hline Female sex & $68(42.2)$ & $151(42.8)$ & 0.01 \\
\hline Race & & & $0.29^{a}$ \\
\hline White & $73(45.3)$ & $199(56.4)$ & \\
\hline Black/African American & $23(14.3)$ & $43(12.2)$ & \\
\hline Asian & $16(9.9)$ & $22(6.2)$ & \\
\hline More than one race & $3(1.9)$ & $12(3.4)$ & \\
\hline Other & $23(14.3)$ & $33(9.4)$ & \\
\hline Unknown & $23(14.3)$ & $44(12.5)$ & \\
\hline Ethnicity & & & 0.14 \\
\hline Hispanic or Latino & $30(18.6)$ & $51(14.5)$ & \\
\hline Not Hispanic or Latino & $113(70.2)$ & $258(73.1)$ & \\
\hline Unknown/not reported & $18(11.2)$ & $44(12.5)$ & \\
\hline Gestational age at birth, wk & $38.4 \pm 2.9$ & $38.5 \pm 3.4, n=350$ & 0.05 \\
\hline Birthweight, kg & $3.1 \pm 0.7, n=160$ & $3.2 \pm 0.8, n=345$ & 0.13 \\
\hline Apgar score: 1 minute & $2(1-5), n=154$ & $5(2-8), n=327$ & $0.68^{a}$ \\
\hline Apgar score: 5 minutes & $4(2-7), n=155$ & $8(5-9), n=326$ & $0.81^{a}$ \\
\hline Apgar score: 10 minutes & $5(3-6), n=106$ & $7(5-8), n=117$ & $0.46^{\mathrm{a}}$ \\
\hline Primary seizure etiology & & & $0.87^{\mathrm{a}}$ \\
\hline Hypoxic-ischemic encephalopathy & $118(73.3)$ & $123(34.8)$ & \\
\hline Hemorrhage & $21(13.0)$ & $73(20.7)$ & \\
\hline Ischemic stroke & $17(10.6)$ & $104(29.5)$ & \\
\hline Other & $5(3.1)$ & $53(15.0)$ & \\
\hline Age at CEEG initiation, $h$ & $11.6(8.2-59)$ & $44.6(20.6-147.6)$ & 0.16 \\
\hline Duration of cEEG, $h$ & $87.0(68.9-101.4)$ & $61.7(40.6-84.0)$ & $0.62^{a}$ \\
\hline Clinical seizures prior to CEEG & $10(6.2)$ & $312(88.4)$ & $2.90^{\mathrm{a}}$ \\
\hline Phenobarbital given prior to CEEG & $8(5.0)$ & $195(55.2)$ & $1.31^{\mathrm{a}}$ \\
\hline Therapeutic hypothermia & $106(66.3)$ & $53(15.0)$ & $1.22^{\mathrm{a}}$ \\
\hline Initial medication used for loading & & & 0.09 \\
\hline Phenobarbital & $148(91.9)$ & $333(94.3)$ & \\
\hline Levetiracetam & $9(5.6)$ & $15(4.3)$ & \\
\hline Phenytoin/fosphenytoin & $2(1.2)$ & $2(0.6)$ & \\
\hline Other & 0 & $1(0.3)$ & \\
\hline No loading dose given & $2(1.2)$ & $2(0.6)$ & \\
\hline High seizure burden at any time during NICU admission & $68(42.2)$ & $199(56.4)$ & $0.28^{a}$ \\
\hline Status epilepticus at any time during NICU admission & $32(19.9)$ & $74(21.0)$ & 0.03 \\
\hline
\end{tabular}

Abbreviation: NICU = neonatal intensive care unit.

Data are presented as $n(\%)$, mean $\pm S D$, or median (interquartile range).

${ }^{a}$ An imbalance between study groups is defined as values greater than 0.20 . 
Table 2 Outcome by Continuous EEG (cEEG) Approach

\begin{tabular}{|c|c|c|c|c|}
\hline & $\begin{array}{l}\text { Screening } \\
\text { cEEG, n (\%) }\end{array}$ & $\begin{array}{l}\text { Confirmatory } \\
\text { cEEG, n (\%) }\end{array}$ & $\begin{array}{l}\text { OR }(95 \% \mathrm{CI}) ; p \text { value } \\
\text { (unadjusted) }\end{array}$ & $\begin{array}{l}\text { OR }(95 \% \mathrm{CI}) ; p \text { value } \\
\left.\text { (adjusted }^{\mathrm{a}}\right)\end{array}$ \\
\hline \multicolumn{5}{|l|}{ Primary analysis } \\
\hline Neonates included & $161(31.3)$ & $353(68.7)$ & & \\
\hline $\begin{array}{l}\text { Successful treatment response } \\
\text { Odds of initial treatment success: screening cEEG vs } \\
\text { confirmatory cEEG }\end{array}$ & $63(39.1)$ & $65(18.4)$ & $2.85(1.88-4.32) ; p<0.0001$ & $2.44(1.45-4.11) ; p=0.0008$ \\
\hline \multicolumn{5}{|c|}{ Subgroup analysis: Hypoxic-ischemic encephalopathy seizure etiology } \\
\hline Neonates included & $118(49)$ & $123(51)$ & & \\
\hline $\begin{array}{l}\text { Successful treatment response } \\
\text { Odds of initial treatment success: screening cEEG vs } \\
\text { confirmatory cEEG }\end{array}$ & $47(39.8)$ & $26(21.1)$ & $2.51(1.42-4.43) ; p=0.002$ & $2.15(1.14-4.04) ; p=0.02$ \\
\hline
\end{tabular}

Abbreviations: $\mathrm{Cl}$ = confidence interval; OR = odds ratio.

${ }^{a}$ Multivariable analysis adjusted for Apgar score at 5 minutes, primary seizure etiology category, presence/absence of multiple seizure etiologies, and whether the patient underwent therapeutic hypothermia.

providing therapeutic hypothermia to neonates with $\mathrm{HIE}$ should also have the ability to provide cEEG or amplitudeintegrated EEG monitoring for seizure detection. ${ }^{13}$ A recent survey of NICU practices in California found the majority of centers performed some degree of EEG monitoring among all neonates undergoing therapeutic hypothermia for HIE. ${ }^{14}$ The goal of using cEEG as a tool to screen for seizures among highrisk neonates is to facilitate earlier and more accurate diagnosis, and thereby more effective treatment, while avoiding ASM administration for seizure mimics.
At the same time, cEEG is resource-intensive, and may not be available for all high-risk neonates at all hospitals. Among neonates with HIE treated with hypothermia, fewer than half have seizures on EEG. ${ }^{15}$ Among groups of newborns with other risk factors, the incidence is even lower. ${ }^{16}$ For this reason, some centers have employed a strategy of initiating cEEG only when there is a clinical suspicion for seizure, such as an abnormal paroxysmal movement suspected to be seizure. This confirmatory cEEG strategy allows lower use of resources than screening all neonates at risk. It is unknown to

Figure 3 Simulation Results Modeling Varied Assumed Treatment Success Rates for Patients With Missing Outcome Data

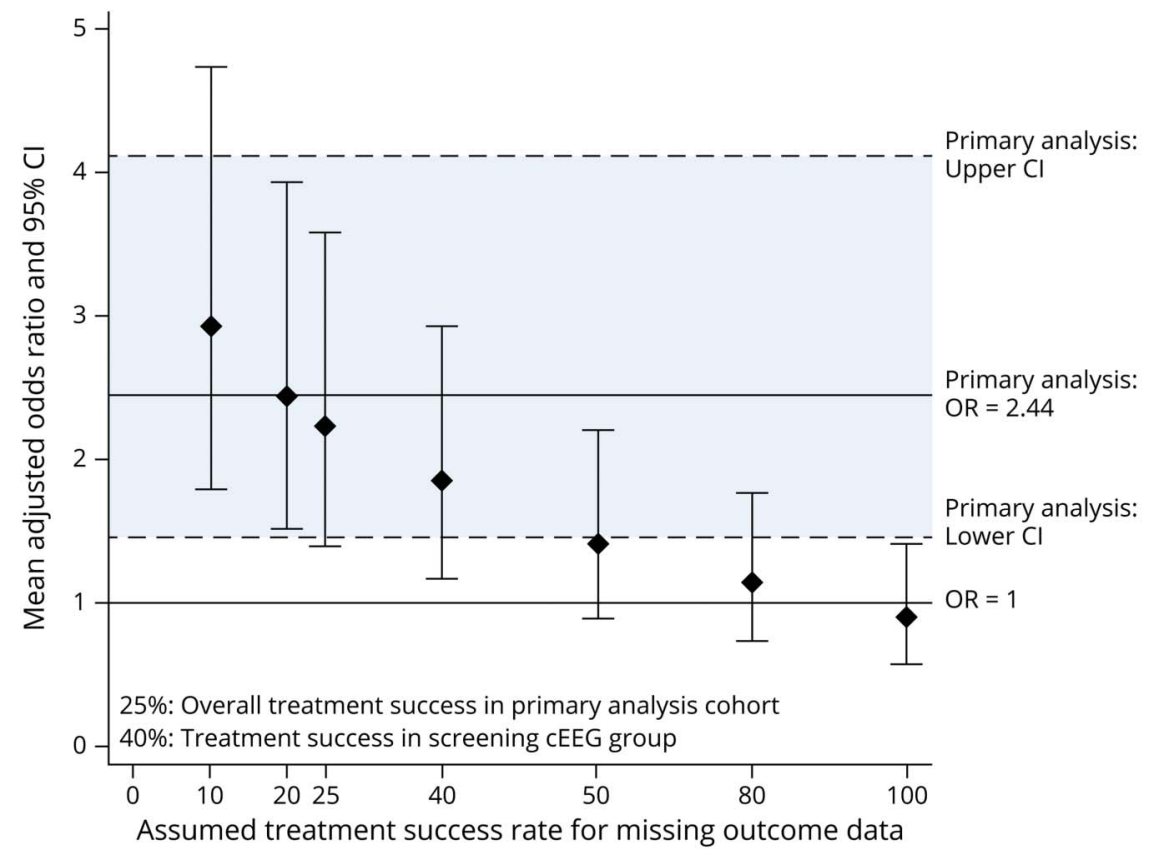

Mean adjusted odds ratio: screening cEEG vs confirmatory cEEG

cEEG = continuous EEG; $\mathrm{Cl}$ = confidence interval; $\mathrm{OR}=$ odds ratio. 
what degree this approach misses high-risk neonates with seizures that do not have clinical manifestations or delays seizure diagnosis and treatment.

There is a paucity of evidence regarding the effect of cEEG strategy on short- and long-term outcomes. A randomized trial of screening vs confirmatory cEEG in neonates at risk for seizures is unlikely to occur, due both to a lack of equipoise at individual centers and the high expense of such a trial. In the absence of a randomized trial, other types of evidence must be sought to understand the effect of cEEG approaches on outcomes.

This study analyzed prospective, observational data from multiple centers to determine the association between cEEG monitoring approach and successful seizure treatment with the first loading dose of ASM. After adjusting for covariates, our results showed that neonates who underwent screening cEEG had more than 2 times greater odds of seizure treatment success as compared to those who underwent confirmatory cEEG. An analysis of only neonates with HIE yielded a similar conclusion: screening cEEG remained associated with more than 2 times greater odds of treatment success than confirmatory cEEG. These data suggest further study is warranted as to how utilization of a screening cEEG approach may facilitate improved successful seizure treatment response in neonates at high risk for seizures, and whether this ultimately affects long-term outcomes.

Strengths of this study include the large number of neonates included and prospective data collection. Because this is an observational study, it is important to recognize that our results showing an association do not prove causation. Our analysis only considered the overall association between cEEG approach and successful response to initial seizure treatment. We were not able to examine all potentially relevant intermediary steps, such as time to cEEG initiation, time to seizure recognition, and time to first ASM administration. However, studies of pediatric patients have found longer duration of seizure prior to treatment is associated with a more refractory course. ${ }^{17,18}$ This may be mediated at a cellular level by the internalization of inhibitory receptors as a result of prolonged seizure, among other mechanisms. ${ }^{19}$ Ongoing research is required to understand better any potential causal relationship between screening cEEG approach and increased success in seizure control. Similarly, there was no significant difference in the specific ASM used between groups, thus further studies are needed to determine whether monitoring approach is a factor in clinician choice of ASM, and how this might affect outcomes. NSR data did not include details on timing of seizure burden or quantification of seizure burden; we were not able to assess how pretreatment seizure burden affected seizure control in each group. Nor were we able to assess all potentially relevant outcome measures, such as reduction in seizure burden in the absence of seizure resolution or long-term outcomes. These are important avenues for future work; long-term neurodevelopmental follow-up is underway for neonates participating in the NSR.
An important limitation is that our primary outcome measure of successful response to initial treatment was defined by cEEG showing resolution of seizures within 30 minutes of first ASM administration. Thus, our primary analysis did not include neonates who never had seizures on cEEG. This necessarily excluded those neonates with clinically diagnosed seizures that resolved prior to initiation of cEEG. Whereas it is unknown whether all of these neonates had true electrographic seizures, each was considered to have seizures by clinical diagnosis upon review by the site investigator. It is likely that most had electro-clinical seizures at the time of diagnosis, and that these resolved at some point prior to cEEG initiation, although not necessarily within 30 minutes of first ASM administration. By excluding neonates who had apparent resolution prior to CEEG, the confirmatory cEEG approach group for the primary analysis may have included a higher proportion of neonates with more treatment-resistant seizures. To address this, we performed sensitivity analysis modeling how our results would change if the excluded neonates had been included; sensitivity analysis supported the findings of our primary analysis.

Similarly, we recognize that whether a neonate receives screening or confirmatory cEEG is not wholly at the discretion of the provider-for example, neonates may be transferred to referral centers only after clinical seizures are recognized. This is reflected in our own results, as 10 neonates had screening cEEG ordered prior to onset of clinical seizures, but then developed clinical seizures in the interval between the decision to order cEEG and initiation of cEEG recording. At the same time, it is possible to set a preferred strategy of screening or confirmatory cEEG for high-risk patients, such as those with HIE, through development of unit guidelines or institutional pathways. Thus, we find evidence to support the use of a screening cEEG approach as clinically relevant even though the option is not available for every patient. Finally, future research should investigate whether the benefit of improved seizure control may be seen with approaches that are less resource-intensive, such as screening cEEG for 24 hours with continued monitoring only for those identified to be at ongoing risk for seizures.

These findings provide evidence from a large, contemporary cohort of neonates that a screening cEEG strategy may improve rates of initial treatment success for acute symptomatic seizures. The use of cEEG to screen high-risk neonates for seizures before clinical seizures occur (screening cEEG) is associated with improved odds of seizure treatment success as compared to performing cEEG only after seizures are observed (confirmatory cEEG). This supports the clinical practice of screening cEEG for seizures in high-risk neonates.

\section{Acknowledgment}

The authors thank the NSR parent partner group for their input toward this project as well as the study coordinators at the NSR centers. 


\section{Study Funding}

NIH grant K02NS102598 (C.J.W.), PCORI CER-1507-31187, Pediatric Epilepsy Research Foundation, Stanford Maternal Child Health Research Institute, NIH K23 NS116453 (M.E.L.), NIH K23 NS092923 (C.J.C.).

\section{Disclosure}

C.J. Wusthoff was funded by NIH grant K02NS102598, PCORI, the Pediatric Epilepsy Research Foundation, and Stanford Maternal Child Health Research Institute, and has served as a consultant for Persyst. V. Sundaram reports no disclosures. N.S. Abend receives research funding from NIH, PCORI, UCB Pharma, Wolfson Family Foundation, and Children's Hospital of Philadelphia; royalties from Demos; and is a consultant for the Epilepsy Foundation. S. Massey reports no disclosures. M.E. Lemmon is funded by NIH grant K23NS116453. C.W. Thomas received research funding from NIH, UCB Pharma, and Cincinnati Children's Hospital. C.E. $\mathrm{McCulloch}$ receives research funding from NIH and PCORI. T. Chang reports no disclosures. J.S. Soul received research funding from NIH and PCORI and received royalties from UpToDate. C.J. Chu receives research funding from the NIH and serves as a consultant for Biogen Inc. and Sleepmed Inc. E.E. Rogers receives research funding from NIH, PCORI, and UCSF. S. Bonifacio reports no disclosures. M.R. Cilio receives research funding from Fond de Recherche Clinique and SaintLuc University Hospital. H.C. Glass received research funding from NIH and PCORI. R.A. Shellhaas receives research funding from NIH, PCORI, the Pediatric Epilepsy Research Foundation, and the University of Michigan; serves as a consultant for the Epilepsy Study Consortium; receives royalties from UpToDate for authorship of topics related to neonatal seizures; and is associate editor for Neurology. Go to Neurology.org/ $\mathrm{N}$ for full disclosures.

\section{Publication History}

Received by Neurology November 29, 2020. Accepted in final form May 3, 2021.

\section{Appendix 1 Authors}

\begin{tabular}{|c|c|c|}
\hline Name & Location & Contribution \\
\hline $\begin{array}{l}\text { Courtney J. } \\
\text { Wusthoff, } \\
\text { MD, MS }\end{array}$ & $\begin{array}{l}\text { Stanford University, Palo } \\
\text { Alto, CA }\end{array}$ & $\begin{array}{l}\text { Designed and conceptualized } \\
\text { the study, analyzed the data, } \\
\text { drafted the manuscript for } \\
\text { intellectual content }\end{array}$ \\
\hline $\begin{array}{l}\text { Vandana } \\
\text { Sundaram, } \\
\text { MPH }\end{array}$ & $\begin{array}{l}\text { Stanford University, Palo } \\
\text { Alto, CA }\end{array}$ & $\begin{array}{l}\text { Designed and performed the } \\
\text { statistical analysis, drafted } \\
\text { figures, revised the } \\
\text { manuscript for intellectual } \\
\text { content }\end{array}$ \\
\hline $\begin{array}{l}\text { Nicholas S. } \\
\text { Abend, MD, } \\
\text { MSCE }\end{array}$ & $\begin{array}{l}\text { University of Pennsylvania, } \\
\text { Philadelphia }\end{array}$ & $\begin{array}{l}\text { Acquisition and interpretation } \\
\text { of data, revised the } \\
\text { manuscript for intellectual } \\
\text { content }\end{array}$ \\
\hline $\begin{array}{l}\text { Shavonne L. } \\
\text { Massey, MD } \\
\text { MSCE }\end{array}$ & $\begin{array}{l}\text { University of Pennsylvania, } \\
\text { Philadelphia }\end{array}$ & $\begin{array}{l}\text { Acquisition and interpretation } \\
\text { of data, revised the } \\
\text { manuscript for intellectual } \\
\text { content }\end{array}$ \\
\hline
\end{tabular}

Appendix 1 (continued)

\begin{tabular}{lll}
\hline Name & Location & Contribution \\
\hline $\begin{array}{l}\text { Monica E. } \\
\text { Lemmon, }\end{array}$ & Duke University, Durham, & $\begin{array}{l}\text { Acquisition and interpretation } \\
\text { of data, revised the } \\
\text { manuscript for intellectual } \\
\text { MD }\end{array}$ \\
& content
\end{tabular}

Cameron W. University of Cincinnati, $\mathrm{OH}$ Acquisition and interpretation Thomas, MD, of data, revised the MS manuscript for intellectual content

\begin{tabular}{lll}
\hline $\begin{array}{l}\text { Charles E. } \\
\text { McCulloch, } \\
\text { PhD }\end{array}$ & $\begin{array}{l}\text { University of California, } \\
\text { San Francisco }\end{array}$ & $\begin{array}{l}\text { Design of the statistical } \\
\text { analysis, revised the } \\
\text { manuscript for intellectual } \\
\text { content }\end{array}$ \\
\hline $\begin{array}{l}\text { Taeun } \\
\text { Chang, MD }\end{array}$ & $\begin{array}{l}\text { George Washington } \\
\text { University School of } \\
\text { Medicine, Washington, DC }\end{array}$ & $\begin{array}{l}\text { Acquisition and interpretation } \\
\text { of data, revised the } \\
\text { manuscript for intellectual } \\
\text { content }\end{array}$ \\
\hline $\begin{array}{l}\text { Janet S. Soul, } \\
\text { MDCM }\end{array}$ & $\begin{array}{l}\text { Harvard Medical School, } \\
\text { Boston, MA }\end{array}$ & $\begin{array}{l}\text { Acquisition and interpretation } \\
\text { of data, revised the } \\
\text { manuscript for intellectual } \\
\text { content }\end{array}$ \\
\hline
\end{tabular}

Catherine J. Harvard Medical School, Acquisition and interpretation Chu, MD, Boston, MA of data, revised the MA, MMSc manuscript for intellectual content

Elizabeth E. University of California, Acquisition and interpretation Rogers, MD San Francisco of data, revised the manuscript for intellectual content

\begin{tabular}{lll}
\hline Sonia L. & Stanford University, Palo & Acquisition and interpretation \\
Bonifacio, & Alto, CA & $\begin{array}{l}\text { of data, revised the } \\
\text { manuscript for intellectual } \\
\text { MD }\end{array}$ \\
& & content
\end{tabular}

M. Roberta Université Catholique de Acquisition and interpretation Cilio, MD, Louvain, Brussels, Belgium of data, revised the

PhD manuscript for intellectual content

Hannah C. University of California, Design and conceptualization Glass, MDCM San Francisco of study cohort, acquisition and interpretation of data, revised the manuscript for intellectual content

\begin{tabular}{lll}
\hline Renée & University of Michigan, Ann & $\begin{array}{l}\text { Design and } \\
\text { conceptualization of study } \\
\text { Shellhaas, }\end{array}$ \\
MD, MS & cohort, acquisition and & \\
& & interpretation of data, \\
& revised the manuscript for \\
& intellectual content
\end{tabular}

Appendix 2 Coinvestigators

\begin{tabular}{|c|c|c|c|}
\hline Name & Location & Role & Contribution \\
\hline $\begin{array}{l}\text { Adam L. } \\
\text { Numis, } \\
\text { MD }\end{array}$ & $\begin{array}{l}\text { University of } \\
\text { California, San } \\
\text { Francisco }\end{array}$ & $\begin{array}{l}\text { Site } \\
\text { investigator }\end{array}$ & $\begin{array}{l}\text { Contributed toward } \\
\text { identification and } \\
\text { enrollment of participants }\end{array}$ \\
\hline $\begin{array}{l}\text { Ronnie } \\
\text { Guillet, } \\
\text { MD, PhD }\end{array}$ & $\begin{array}{l}\text { University of } \\
\text { Rochester, NY }\end{array}$ & Coinvestigator & $\begin{array}{l}\text { Provided input on NSR } \\
\text { study processes }\end{array}$ \\
\hline $\begin{array}{l}\text { Linda S. } \\
\text { Franck, } \\
\text { RN, PhD }\end{array}$ & $\begin{array}{l}\text { University of } \\
\text { California, San } \\
\text { Francisco }\end{array}$ & Coinvestigator & $\begin{array}{l}\text { Provided input on NSR } \\
\text { study processes }\end{array}$ \\
\hline
\end{tabular}


Appendix 2 (continued)

\begin{tabular}{llll}
\hline Name & Location & Role & Contribution \\
\hline $\begin{array}{l}\text { Marty } \\
\text { Barnes }\end{array}$ & Austin, TX & $\begin{array}{l}\text { Parent } \\
\text { partner }\end{array}$ & $\begin{array}{l}\text { Provided parental } \\
\text { perspective toward NSR } \\
\text { study processes }\end{array}$ \\
\hline $\begin{array}{l}\text { Tammy } \\
\text { Tsuchida, } \\
\text { MD }\end{array}$ & $\begin{array}{l}\text { Children's } \\
\text { National Hospital, }\end{array}$ & Coinvestigator & $\begin{array}{l}\text { Contributed toward } \\
\text { identification and } \\
\text { enrollment of participants }\end{array}$ \\
\hline & & &
\end{tabular}

\section{References}

1. Glass HC, Soul JS, Chu CJ, et al; Neonatal Seizure Registry study group. Response to antiseizure medications in neonates with acute symptomatic seizures. Epilepsia. 2019; 60(3):e20-e24.

2. Shellhaas RA, Chang T, Tsuchida T, et al. The American Clinical Neurophysiology Society's Guideline on continuous electroencephalography monitoring in neonates. J Clin Neurophysiol. 2011;28(6):611-617.

3. Glass HC, Shellhaas RA, Tsuchida TN, et al. Seizures in preterm neonates: a multicenter observational cohort study. Pediatr Neurol. 2017;72:19-24.

4. Shellhaas RA, Chang T, Wusthoff CJ, et al. Treatment duration after acute symptomatic seizures in neonates: a multicenter cohort study. J Pediatr. 2017;181:298-301.

5. Glass HC, Shellhaas RA, Wusthoff CJ, et al. Contemporary profile of seizures in neonates: a prospective cohort study. J Pediatr. 2016;174:98-103.

6. Yang D, Dalton J. A unified approach to measuring the effect size between two groups using SAS. Presented at the 2012 SAS Global Forum: Statistics and Data Analysis; Paper 335-2012; Orlando, FL; support.sas.com/resources/papers/proceedings12/ 335-2012.pdf (accessed 29 November 2020).
7. Painter MJ, Scher MS, Stein AD, et al. Phenobarbital compared with phenytoin for the treatment of neonatal seizures. N Engl J Med. 1999;341(7):485-489.

8. Boylan GB, Rennie JM, Pressler RM, Wilson G, Morton M, Binnie CD. Phenobarbitone, neonatal seizures, and video-EEG. Arch Dis Child Fetal Neonatal Ed. 2002; 86(3):F165-F170.

9. Sharpe C, Reiner GE, Davis SL, et al. Levetiracetam versus phenobarbital for neonatal seizures: a randomized controlled trial. Pediatrics. 2020;147(1):e20193182.

10. Clancy RR, Legido A, Lewis D. Occult neonatal seizures. Epilepsia. 1988;29(3): 256-261.

11. Murray DM, Boylan GB, Ali I, Ryan CA, Murphy BP, Connolly S. Defining the gap between electrographic seizure burden, clinical expression and staff recognition of neonatal seizures. Arch Dis Child Fetal Neonatal Ed. 2008;93(3):F187-F191.

12. Worden LT, Chinappen DM, Stoyell SM, et al. The probability of seizures during continuous EEG monitoring in high-risk neonates. Epilepsia. 2019;60(12):2508-2518.

13. Committee on Fetus and Newborn, Papile LA, Baley JE, Benitz W, et al. Hypothermia and neonatal encephalopathy. Pediatrics. 2014;133(6):1146-1150.

14. Wusthoff CJ, Clark CL, Glass HC, et al. Cooling in neonatal hypoxic-ischemic encephalopathy: practices and opinions on minimum standards in the state of California. J Perinatol. 2018;38(1):54-58.

15. Glass HC, Wusthoff CJ, Shellhaas RA, et al. Risk factors for EEG seizures in neonates treated with hypothermia: a multicenter cohort study. Neurology. 2014;82(14): 1239-1244.

16. Abend NS, Wusthoff CJ, Goldberg EM, et al. Electrographic seizures and status epilepticus in critically ill children and neonates with encephalopathy. Lancet Neurol. 2013;12(12):1170-1179.

17. Eriksson $\mathrm{K}$, Metsäranta $\mathrm{P}, \mathrm{Huhtala} \mathrm{H}$, et al. Treatment delay and the risk of prolonged status epilepticus. Neurology. 2005;65(8):1316-1318.

18. Williams RP, Banwell B, Berg RA, et al. Impact of an ICU EEG monitoring pathway on timeliness of therapeutic intervention and electrographic seizure termination. Epilepsia. 2016;57(5):786-795.

19. Goodkin HP, Yeh JL, Kapur J. Status epilepticus increases the intracellular accumulation of GABAA receptors. J Neurosci. 2005;25(23):5511-5520. 


\section{Neurology}

Seizure Control in Neonates Undergoing Screening vs Confirmatory EEG Monitoring Courtney J. Wusthoff, Vandana Sundaram, Nicholas S. Abend, et al. Neurology 2021;97;e587-e596 Published Online before print June 2, 2021 DOI 10.1212/WNL.0000000000012293

This information is current as of June 2, 2021

\section{Updated Information \& Services}

References

Subspecialty Collections

Permissions \& Licensing

\section{Reprints}

including high resolution figures, can be found at: http://n.neurology.org/content/97/6/e587.full

This article cites 18 articles, 5 of which you can access for free at: http://n.neurology.org/content/97/6/e587.full\#ref-list-1

This article, along with others on similar topics, appears in the following collection(s):

\section{Class III}

http://n.neurology.org/cgi/collection/class_iii

Critical care

http://n.neurology.org/cgi/collection/critical_care

EEG

http://n.neurology.org/cgi/collection/eeg_

EEG; see Epilepsy/Seizures

http://n.neurology.org/cgi/collection/eeg_see_epilepsy-seizures

Neonatal

http://n.neurology.org/cgi/collection/neonatal

Neonatal seizures

http://n.neurology.org/cgi/collection/neonatal_seizures

Information about reproducing this article in parts (figures,tables) or in its entirety can be found online at:

http://www.neurology.org/about/about_the_journal\#permissions

Information about ordering reprints can be found online:

http://n.neurology.org/subscribers/advertise

Neurology ${ }^{\circledR}$ is the official journal of the American Academy of Neurology. Published continuously since 1951, it is now a weekly with 48 issues per year. Copyright Copyright @ 2021 The Author(s). Published by Wolters Kluwer Health, Inc. on behalf of the American Academy of Neurology.. All rights reserved. Print ISSN: 0028-3878. Online ISSN: 1526-632X.

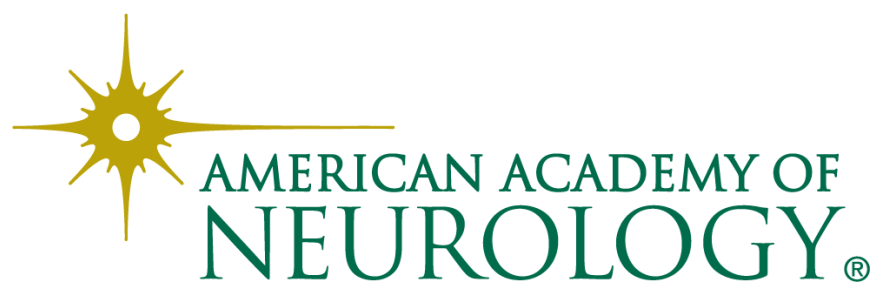

